\title{
ANALISIS PRODUKTIVITAS MESIN SHEATING 3 DENGAN METODE OVERALL EQUIPMENT EFFECTIVENESS (OEE) PADA PRODUKSI FIBER OPTIC PT VOKSEL ELECTRIC TBK
}

\author{
Riana Magdalena, Amelia Pricilla Ginting \\ Program Studi Teknik Industri, Universitas Katolik Indonesia Atma Jaya \\ Jl. Raya Cisauk Lapan No.10, Tangerang, Banten 15345 \\ e-mail: riana.magdalena@atmajaya.ac.id, pricillaginting@gmail.com
}

\begin{abstract}
ABSTRAK
Perkembangan Industri pada jaman sekarang ini sangatlah pesat, akibatnya terdapat persaingan yang ketat antar perusahaan khususnya pada bidang produksi. Target produksi serta Produktivitas dari tiap mesin merupakan salah satu pencapaian yang harus dilakukan secara konstan dalam keseimbangan produksi dari perusahaan sehingga dapat menjaga mutu dari produk yang dihasilkan. PT. Voksel Electric Tbk merupakan salah satu perusahaan yang bergerak dalam bidang telekomunikasi. Terjadinya kerusakan pada mesin-mesin dapat menyebabkan turunnya pencapaian target serta produktivitas itu sendiri salahsatunya adalah Mesin Sheating 3 dimana terdapat 7680 menit kerusakan dibandingkan dengan mesin lainnya. Untuk mengetahui faktor-faktor yang dapat menyebabkan produktivitas pada mesin sheating 3 ini maka penelitian ini menggunakan metode Overall Equipment Effectiveness (OEE) dan juga menganalisis dengan bantuan Six Big Losses serta Fishbone. Metode OEE pada penelitian ini digunakan untuk mengetahui seberapa besar produktivitas yang dihasilkan oleh mesin-mesin khususnya mesin sheating 3. Mesin Sheating 3 ini memiliki nilai OEE sebesar 26,02\% yang tergolong sangat rendah dibandingkan dengan standar nilai OEE. Analisis dengan bantuan Six Big Losses menyatakan bahwa kerugian yang paling besar terdapat pada Idling and Minor Stoppages $(38,02 \%)$ dan Redeuced Speed $(19,46)$. Usulan dilakukan dengan bantuan FMEA (Failure Modes\&Effect Analysis) kepada 2 kerugian penyebab dari menurunnya produktivitas serta faktor-faktor yang disebabkan yang telah ditentukan dengan bantuan fishbone.
\end{abstract}

Kata kunci: Produktivitas,FMEA, Overall Equipment Effectiveness (OEE), Six Big Losses.

\begin{abstract}
The development of the industry at this time is very rapid, as a result, there is intense competition between companies, especially in the field of production. Production targets and productivity of each machine is one achievement that must be done constantly in the balance of production of the company so that it can maintain the quality of the products produced. PT. Voksel Electric Tbk is a company engaged in telecommunications. The occurrence of damage to the machines can cause a decrease in target achievement and productivity itself, one of which is the Sheating Machine 3 where there are 7680 minutes of damage compared to other machines. To find out the factors that can cause productivity on this sheating 3 machine, this study uses the Overall Equipment Effectiveness (OEE) method and also analyzes with the help of Six Big Losses and Fishbone. The OEE method in this study is used to find out how much productivity is produced by machines, especially the sheating machine 3. The Sheating 3 machine has an OEE value of $26.02 \%$ which is classified as very low compared to the standard OEE value. Analysis with the help of Six Big Losses stated that the biggest losses were found in Idling and Minor Stoppages (38.02\%) and Reduced Speed (19.46). The proposal was carried out with the help of FMEA (Failure Modes \& Effect Analysis) to 2 loss causes of decreased productivity and the factors caused that have been determined with the help of fishbone.
\end{abstract}

Keywords: Produktivity, FMEA, Overall Equipment Effectiveness (OEE), Six Big Losses.

\section{PENDAHULUAN}

Perusahaan akan menetapkan target produksi dengan melihat pesanan di masa lalu untuk memperkirakan produksi untuk masa depan. Terhentinya mesin atau teknologi pada saat proses produksi merupakah salah satu faktor yang dapat menyebabkan target produksi dari perusahaan itu sendiri tidak tercapai. Terhentinya mesin tersebut dapat disebabkan karena kerusakan mesin-mesin yang terdeteksi maupun tidak terdeteksi selama proses produksi tersebut yang dapat menghasilkan produk yang cacat atau produk yang perlu 
dikerjakan ulang atau direparasi. Pentingnya perawatan mesin untuk menghindari risiko risiko yang akan terjadi. Perawatan mesin didefinisikan sebagai bentuk kegiatan yang dilakukan untuk mencapai hasil yang mampu mengembalikan item atau mempertahankannya pada kondisi yang selalu dapat berfungsi, perawatan juga merupakan kegiatan pendukung yang menjamin kelangsungan mesin dan peralatan sehingga pada saat dibutuhkan dapat dipakai sesuai dengan yang diharapkan [1].

PT. Voksel Electric Tbk merupakan sebuah perusahaan yang memproduksi kabel berbasis jaringan. PT. Voksel Electric Tbk belom mempunyai penilaian produktivitas secara berkala, sehingga apabila terdapat kerusakan hanya mengandalkan bagian maintenance tanpa mengetahui penyebab dasar dari seringnya kerusakan itu terjadi. Dalam 6 bulan bahwa terdapat 7680 menit kerusakan pada salah satu mesin yaitu mesin sheating 3. Mesin sheating adalah mesin yang digunakan dalam proses akhir dari pembuatan kabel, dengan kata lain mesin ini merupakan mesin yang digunakan untuk proses memberikan jaket kepada kabel yang telah di gabungkan semua elemen-elemennya. Dalam mengatasi penurunan produktivitas yang terjadi pada perusahaan ini diketahui perlu diadakan pemeliharaan mesin dan peralatan yang ada. Salah satunya adalah dengan menerapkan TPM (Total Productive Maintenance). TPM (Total Productive Maintenance) adalah suatu program untuk mengembangkan fundamental dari fungsi pemeliharaan dalam suatu organisasi. Tool yang akan digunakan dalam meningkatkan TPM adalah dengan menggunakan metode Overall Equipment Effectiveness (OEE).

Penelitian ini dilakukan dengan mengukur produktivitas dengan menggunakan metode OEE Pengukuran OEE berfungsi sebagai pengukuran performansi perawatan berdasarkan kondisi mesin untuk melihat secara keseluruhan efektivitas mesin. OEE adalah hasil yang dapat dinyatakan sebagai rasio output aktual dari peralatan dibagi dengan output maksimum peralatan di bawah kondisi performa terbaik [2]. Metode OEE memperhitungkan tingkat keefektifan fasilitas secara menyeluruh yang diperoleh dengan mengalikan Availability Rate, Performance Rate dan Quality Rate [3]. Dari hasil metode OEE dapat diketahui nilai produktivitas dari mesin sheating 3 yang akan dilakukan analisis lanjutan dengan bantuan Six big losses. Six big Losses analisis yang dilihat berdasarkan 6 kerugian peralatan yang menyebabkan rendahnya kinerja dari mesin dan peralatan. 6 kerugian tersebut akan dianalisis masing-masing diantaranta adalah breakdown loss, setup/adjusment losses, idling and minor stoppages, reduce speed, reduces yield [4].

\section{METODE PENELITIAN \\ Pengumpulan Data}

Data-data yang digunakan selama penelitian ini dilakukan adalah sebagai berikut:

1. Data Primer

Data yang didapatkan secara langsung oleh peneliti sesuai dengan latar belakang atau permasalahan yang dialami oleh perusahaan. Data primer yang digunakan dalam penelitian ini merupakan data wawancara pada supervisor mengenai permasalahan yang ada.

2. Data Sekunder

Data yang didapatkan dari buku, jurnal, materi kuliah, serta data-data historis dari perusahaan yang diperlukan pada penelitian ini. Data Sekunder yang digunakan dalam penelitian ini adalah sebagai berikut:

- Data Breakdown Time

- Data Setup Time

- Data Rekapan Jam Kerja untuk setiap bulan

- Data Hasil Produksi (Good Product dan Reject Product) 


\section{Metode Overall Equipment Effectiveness (OEE)}

Langkah-langkah yang dilakukan dalam penelitian ini adalah sebagai berikut [5]:

1. Melakukan perhitungan untuk Availability Rate, perhitungan ini dilakukan guna mengetahui tingkat efektivitas beroperasinya suatu mesin atau peralatan. Untuk mendapatkan perhitungan ini diperlukannya perhitungan seperti available time (1), planned downtime (2), loading time (3), downtime (4), operation time (5), dimana dapat dihitungan dengan menggunakan rumus berikut:

\{Banyaknya jam kerja dalam satu hari $\mathrm{x}$ banyaknya shift $\mathrm{x}$ Hari kerja dalam sebulan\}

$\{1$ minggu $\mathrm{x}$ jumlah jam perawatan yang dilakukan dalam sebulan $\}$

\{Available Time - Planned downtime

\{Waktu Breakdown + Waktu Setup

\{Loading Time - Downtime $\}$

Dengan melakukan perhitungan di atas maka akan didapatkan nilai Availability Rate, dengan melakukan perhitungan sebagai berikut (Tabel 1):

Availability Rate: $\frac{\text { operating Time }}{\text { Loading Time }} \times 100 \%$

Tabel 1. Availability Rate pada Mesin Sheating 3 (menit)

\begin{tabular}{cccccccc}
\hline No & Periode & $\begin{array}{c}\text { Available } \\
\text { Time }\end{array}$ & $\begin{array}{c}\text { Planned } \\
\text { Downtime }\end{array}$ & $\begin{array}{c}\text { Loading } \\
\text { Time }\end{array}$ & Downtime & $\begin{array}{c}\text { Operation } \\
\text { Time }\end{array}$ & $\begin{array}{c}\text { Availability } \\
\text { Rate (\%) }\end{array}$ \\
\hline 1 & Jan & 28620 & 1080 & 27540 & 5026 & 22514 & 81,75 \\
2 & Feb & 30960 & 1800 & 29160 & 5086 & 24074 & 82,56 \\
3 & Mar & 33840 & 1440 & 32400 & 3560 & 28840 & 89,01 \\
4 & Apr & 34380 & 1440 & 32940 & 2732 & 30208 & 91,71 \\
5 & Mei & 32400 & 1800 & 30600 & 4497 & 26103 & 85,3 \\
6 & Jun & 19440 & 1080 & 18360 & 2367 & 15993 & 87,11 \\
\hline \multicolumn{7}{c}{ Rata-Rata } \\
\hline
\end{tabular}

2. Melakukan perhitungan untuk Performance Rate, perhitungan ini dilakukan guna mengetahui kemampuan dari peralatan dalam menghasilkan barang atau produk. Untuk mendapatkan perhitungan ini diperlukannya perhitungan ideal cycle time terlebih dahulu, dimana dapat dilakukan perhitungan sebagai berikut:

$$
\text { Ideal Cycle Time }=\frac{1}{\text { banyaknya produk dihasilkan dalam menit }}
$$

Dengan melakukan perhitungan di atas maka akan didapatkan nilai Performance Rate, dengan melakukan perhitungan sebagai berikut (Tabel 2):

$$
\text { Performance Rate }=\frac{\text { Ideal Cycle Time } x \text { Good Product }}{\text { Operation Time }} \times 100 \%
$$

Tabel 2. Performance Rate pada Mesin Sheating 3 (menit)

\begin{tabular}{cccccc}
\hline No & Periode & $\begin{array}{c}\text { Processed } \\
\text { Amount (Core) }\end{array}$ & $\begin{array}{c}\text { Operation } \\
\text { Time (menit) }\end{array}$ & $\begin{array}{c}\text { Ideal Cycle } \\
\text { Time (menit) }\end{array}$ & $\begin{array}{c}\text { Performance } \\
\text { Rate (\%) }\end{array}$ \\
\hline 1 & Jan & 1390899 & 22514 & 0,4 & 24,71 \\
2 & Feb & 2149086 & 24074 & 0,4 & 35,71 \\
3 & Mar & 2686408 & 28840 & 0,4 & 37,26 \\
4 & Apr & 1876989 & 30208 & 0,4 & 24,85 \\
5 & Mei & 1834703 & 26103 & 0,4 & 28,11 \\
6 & Jun & 1195077 & 15993 & 0,4 & 29,89 \\
\hline \multicolumn{7}{r}{ Rata-Rata } \\
\hline
\end{tabular}

3. Melakukan perhitungan untuk Quality Rate (Table 3), perhitungan ini dilakukan guna mengetahui rasio antara produk yang baik yang sesuai dengan spesifikasi kualitas yang telah ditetapkan terhadap jumlah produk yang diproses. Pehitungan dilakukan dengan menggunakan rumus sebagai berikut: 
Riana Magdalena, Amelia Pricilla Ginting

$$
\text { Quality Rate }=\frac{\text { Good Product }- \text { Reject Product }}{\text { Good Product }} \times 100 \%
$$

Tabel 3. Performance Rate pada Mesin Sheating 3 (menit)

\begin{tabular}{ccccc}
\hline No & Periode & Good Product $(\mathbf{m})$ & Reject Product $(\boldsymbol{m})$ & Quality Rate (\%) \\
\hline 1 & Jan & 1390899 & 12569 & 99,10 \\
2 & Feb & 2149086 & 20478 & 99,05 \\
3 & Mar & 2686408 & 24428 & 99,09 \\
4 & Apr & 1876989 & 15768 & 99,16 \\
5 & Mei & 1834703 & 21637 & 98,82 \\
6 & Jun & 1195077 & 13308 & 98,89 \\
\hline \multicolumn{7}{r}{ Rata-Rata } \\
\hline
\end{tabular}

4. Melakukan perhitungan OEE dengan mengalikan 3 aspek yang telah dihitung di atas dengan rumus sebagai berikut:

$$
\mathrm{OEE}=\mathrm{A} \times \mathrm{P} \times \mathrm{Q} \times 100 \%
$$

5. Menghitung 6 kerugian yang dapat menjadi penyebab (Six Big Losses) dimana perhitungan ini melibatkan antara lain Brekdown loss (11), Setup/Adjusment Losses (12), Idling and Minor Stoppages (13), Reduced Speed, Defect Losses (14), Reduced Yiels (15).

$$
\begin{aligned}
& \mathrm{BL}=\frac{\text { Breakdown time }}{\text { loading time }} \times 100 \% \\
& \mathrm{SL}=\frac{\text { Setup } / \text { Adjustmen } \text { Losses }}{\text { loading time }} \times 100 \% \\
& \mathrm{IMS}=\frac{(\text { Target Produksi-jumlah produksi) } x \text { Cycle time }}{\text { loading time }} \times 100 \% \\
& \mathrm{RS}=\frac{(\text { Actual cycle time-ideal cycle time }) \times \text { total produk }}{\text { loading time }} \times 100 \% \\
& \mathrm{DL}=\frac{(\text { total reject } \times \text { ideal cycle time })}{\text { loading time }} \times 100 \%
\end{aligned}
$$

6. Melakukan Analisa dengan mencari 2 akibat yang paling utama dengan menggunakan pareto diagram, yang kemudian akan di rumuskan lagi penyebab dari permasalahan yang ada dengan menggunakan fishbone serta wawancara dengan pihak perusahaan.

7. Memberikan usulan dengan bantuan FMEA, dengan memberikan usulan dapat dilakukan untuk mengatasi atau mengurangi penyebab tersebut.

\section{HASIL DAN PEMBAHASAN}

Hasil dari perhitungan OEE untuk mesin sheating 3 pada PT. Voksel Electrik Tbk diperoleh dalam 6 bulan terakhir (Januari- Juni) adalah sebagai berikut (Tabel 4):

Tabel 4. Nilai OEE pada Mesin Sheating 3

\begin{tabular}{cccccc}
\hline No & Periode & $\begin{array}{c}\text { Availability } \\
\text { Rate (\%) }\end{array}$ & $\begin{array}{c}\text { Performance Rate } \\
(\mathbf{\%})\end{array}$ & $\begin{array}{c}\text { Quality } \\
\text { Rate (\%) }\end{array}$ & $\begin{array}{c}\text { OEE } \\
(\boldsymbol{\%})\end{array}$ \\
\hline 1 & Jan & 81,75 & 24,71 & 99,10 & 25,74 \\
2 & Feb & 82,56 & 35,71 & 99,05 & 26,29 \\
3 & Mar & 89,01 & 37,26 & 99,09 & 25,89 \\
4 & Apr & 91,71 & 24,85 & 99,16 & 25,85 \\
5 & Mei & 85,30 & 28,11 & 98,82 & 26,16 \\
6 & Jun & 87,11 & 29,89 & 98,89 & 26,18 \\
\hline \multicolumn{6}{c}{ Rata-rata Nilai OEE } \\
\hline
\end{tabular}

Berdasarkan nilai OEE Tabel 4 didapatkan bahwa rata-rata selama 6 bulan mesin Sheating 3 ini mendapatkan nilai 26,02\%, dimana memiliki nilai dibawah dengan standar yang telah ditetapkan yaitu $85 \%$. Sehingga diperlukannya analisis lebih lanjut penyebab dari persentase produktivitas mesin tersebut dengan menggunakan Six Big Losses. 
Tabel 5. Hasil Six Big Losses

\begin{tabular}{cccccccc}
\hline No & Periode & $\begin{array}{c}\text { Breakdown } \\
\text { Loss }\end{array}$ & $\begin{array}{c}\text { Setup/ } \\
\text { Adjustment Loss }\end{array}$ & $\begin{array}{c}\text { Idling and } \\
\text { Minor Stoppages }\end{array}$ & $\begin{array}{c}\text { Reduced } \\
\text { Speed }\end{array}$ & $\begin{array}{c}\text { Defect } \\
\text { Losses }\end{array}$ & $\begin{array}{c}\text { Reduced } \\
\text { Yield }\end{array}$ \\
\hline 1 & Jan & 0,08 & 0,10 & 37,83 & 15,15 & 0,18 & 0 \\
2 & Feb & 0,08 & 0,09 & 35,73 & 22,11 & 0,28 & 0 \\
3 & Mar & 0,04 & 0,07 & 32,15 & 24,87 & 0,30 & 0 \\
4 & Apr & 0,01 & 0,07 & 31,63 & 17,09 & 0,19 & 0 \\
5 & Mei & 0,03 & 0,12 & 34,04 & 17,99 & 0,28 & 0 \\
6 & Jun & 0,02 & 0,11 & 56,74 & 19,53 & 0,29 & 0 \\
\hline \multicolumn{2}{r}{ Rata-Rata } & 0,04 & 0,09 & 38,02 & 19,46 & 0,25 & 0,00 \\
\hline
\end{tabular}

Berdasarkan data yang didapat dalam Tabel 5 diketahui bahwa perhitungan tersebut didapatkan dari masing-masing kerugian pada setiap bulan. Diketahui bahwa penyebab utama dari turunnya produktivitas ini adalah dengan menggunakan prinsip 80/20 dimana yang dapat diartikan sekitar $80 \%$ dari kerugian yang terjadi disesababkan oleh $20 \%$ dari penyebab kerugian lainnya, sehingga nilai $80 \%$ merupakan cacat dominan yang harus dianalisa lebih lanjut untuk mengetahui akar permasalahan. Berdasarkan nilai Pareto Diagram dapat diketahui bahwa nilai $80 \%$ berada di dalam 2 elemen kerugian yaitu Idling and Minor Stoppages $(65,71 \%)$ dan juga Reduced Speed $(33,63 \%)$ seperti pada Gambar 1. Kedua elemen tersebut memiliki persentase yang paling berpengaruh dalam kerugian turunnya nilai produktivitas atau rendahnya nilai OEE yang dihasilkan.

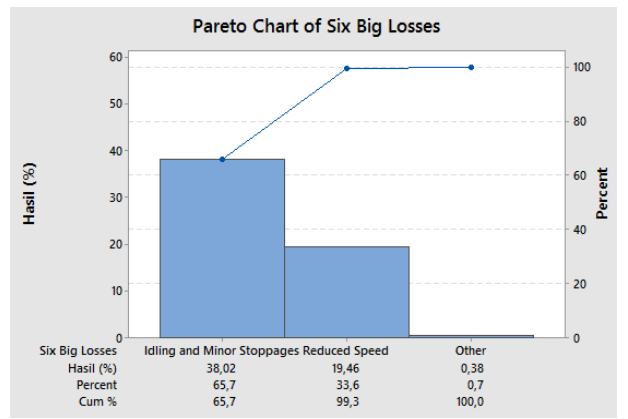

Gambar 1. Pareto Diagram pada Six Big Losses

Akar permasalahan yang utama terdapat pada 2 kerugian yang paling sering terjadi (Gambar 2, Gambar 3), untuk dapat mengetahui sebab dan akibat dari masing-masing kerugian tersebut. Kerugian atau masalah ini dapat terjadi dikarenakan empat aspek yang diamati yaitu mesin/peralatan, metode, bahan atau material dan manusia. Dari akar akar penyebab dari permasalahan akan dilakukan usulan untuk perusahaan, dimana dilakukan dengan bantuan FMEA (Failure Modes and Effect Analysis). FMEA sendiri terdapat nilai severity, occurance dan detection yang akan diisi oleh perusahaan sesuai dengan tingkat keparahan yang akan dikadikan satu nilai tunggal pada nilai RPN seperti pada Tabel 6 dan Tabel 7. Nilai RPN adalah penyebab yang segera harus diambil tindakan lebig cepat dibandingkan lainnya.

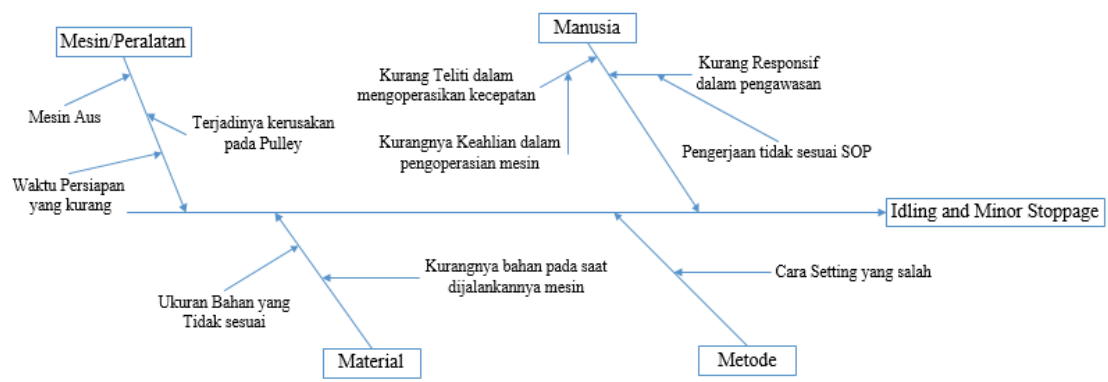

Gambar 2. Fishbone untuk Idling and Minor Stoppage 


\section{Riana Magdalena, Amelia Pricilla Ginting}

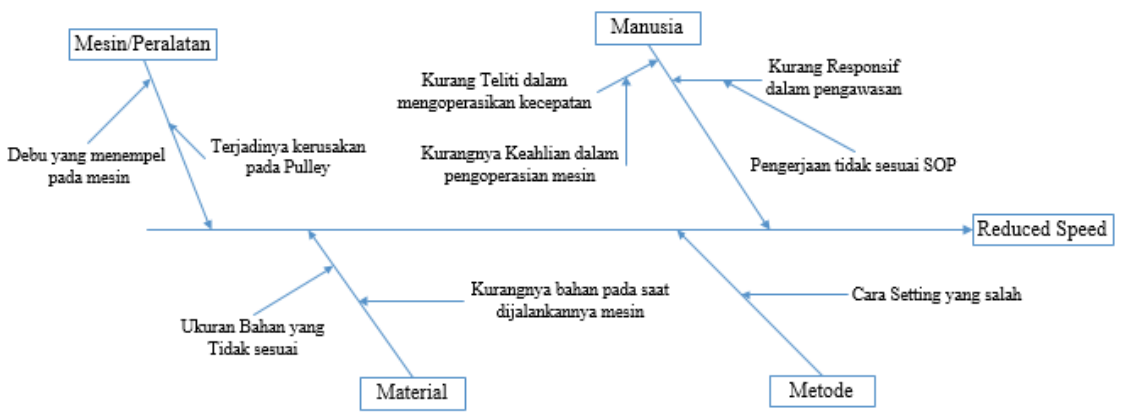

Gambar 3. Fishbone untuk Reduced Speed

FMEA diharapkan memberikan usulan tersebut diharapkan untuk mencegah potensi kegagalan, Tabel 6 dan Tabel 7 FMEA memberikan usulan perbaikan sesuai dengan penguraian bedasarkan diagram sebab akibat, dimana dalam setiap aspek memiliki usulan atau solusi untuk perbaikan.

Tabel 6. FMEA untuk Pernyebab Idling and Minor Stoppage

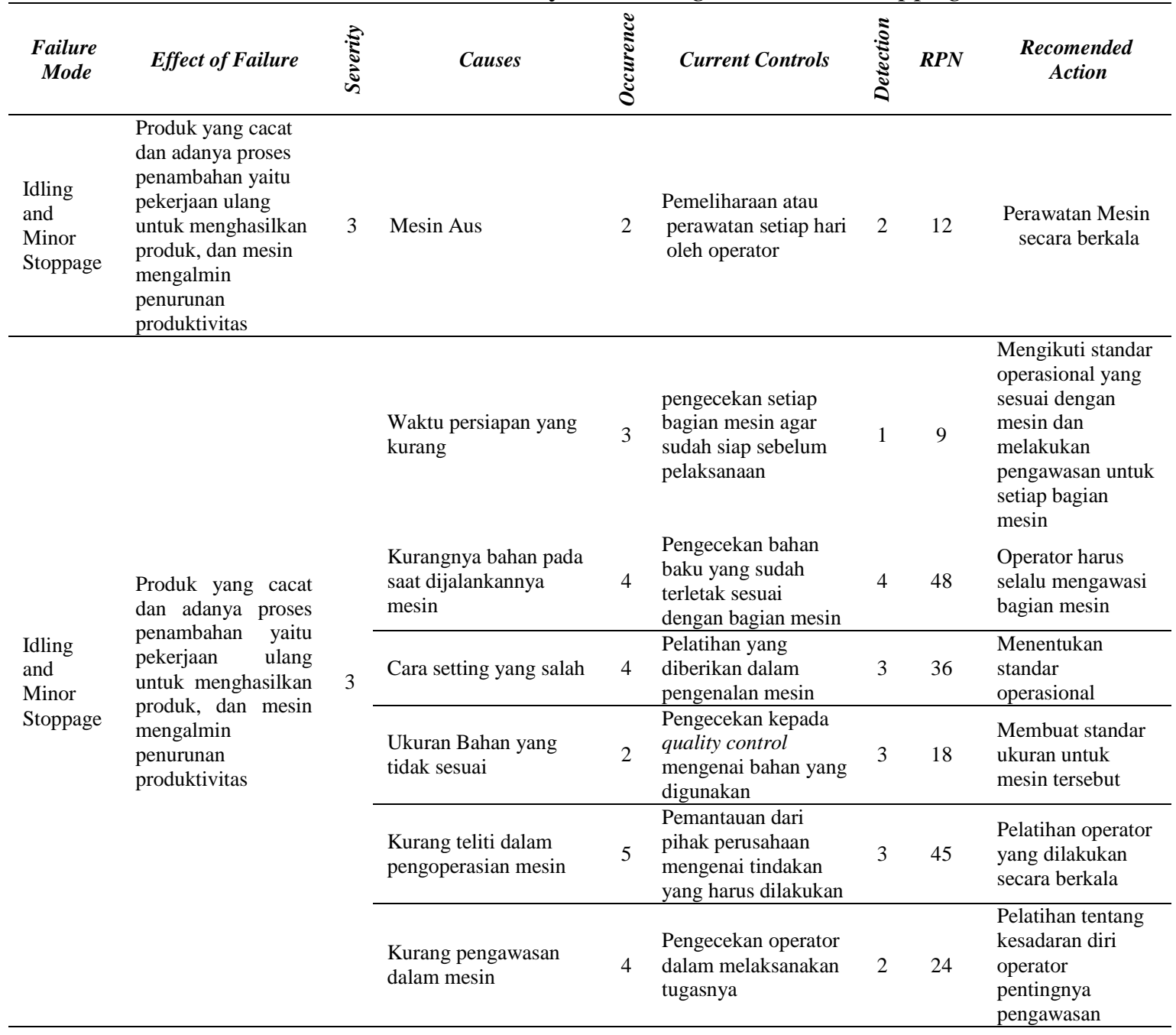


Tabel 7. FMEA untuk Pernyebab Reduced Speed

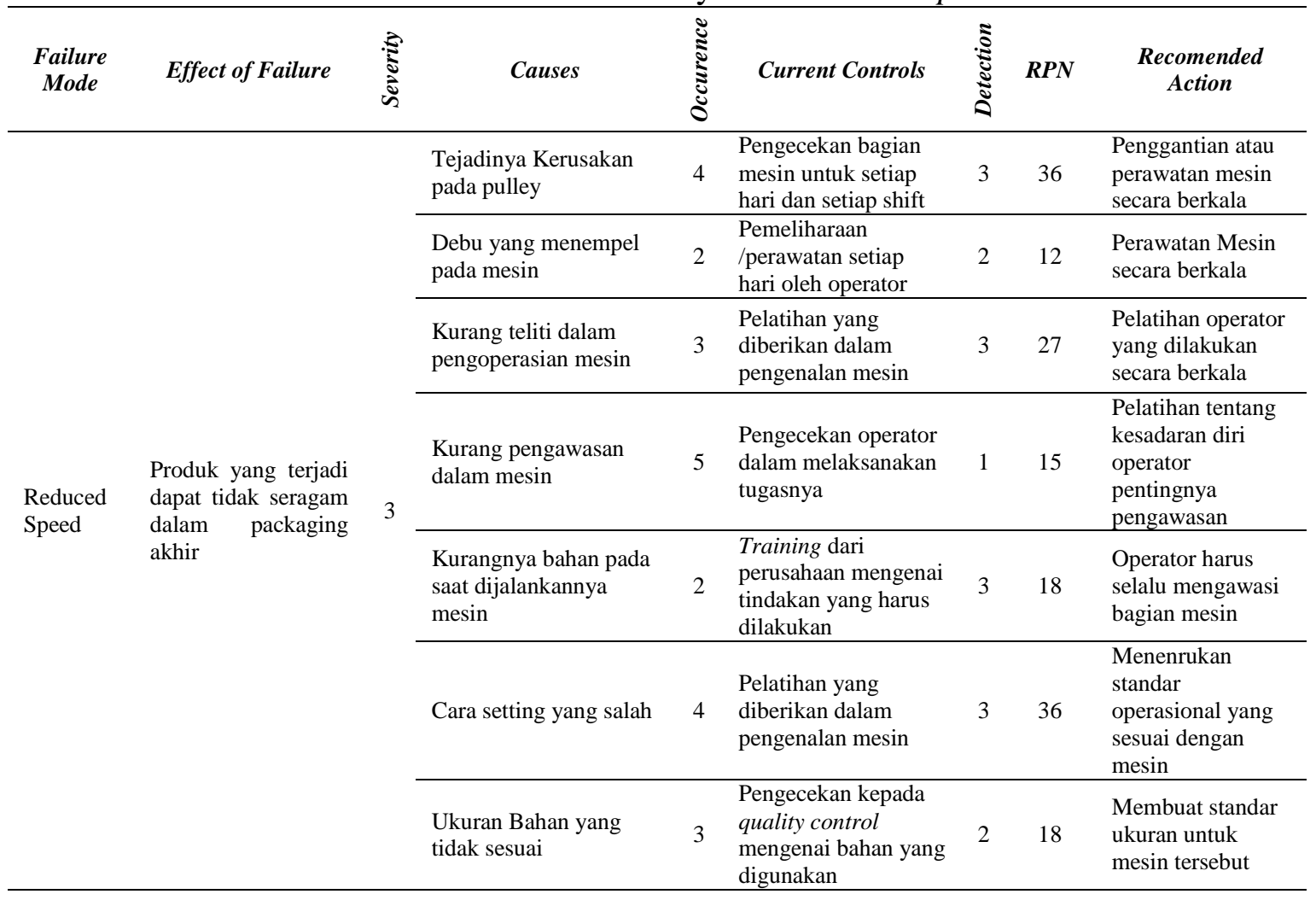

\section{KESIMPULAN}

Hasil yang didapatkan dari perhitungan produktivitas OEE dapat dikatakan bahwa nilai produktivitas mesin sheating 3 tergolong rendah dengan standart OEE yang telah ada yaitu $85 \%$ yaitu sebesar $26,02 \%$. Dimana dengan nilai produktivitas yang turun dapat menyebebkan target produksi pada perusahaan seringkali tidak sesuai dengan planning. Dilakukan perhitungan six big losses dimana untuk mengetahui penyebab mana yang paling sering terjadi atau menjadi penyebab utama dari turunnya produktivitas mesin sheating 3.

Idling and Minor Stoppage serta Reduced Speed merupakan 2 penyebab utama yang dihasilkan dari pareto diagram. Dimana Idling and Minor Stoppage adalah terhentinya mesin pada sat proses produksi sedang berjalan, dan juga reduced speed adalah kecepatan mesin yang tidak seimbang dengan proses produksi. 2 Hal ini dilakukan analisis lebih lanjut agar dapat dilakukan perbaikan.

Kerugian atau masalah ini dapat terjadi dikarenakan empat aspek yang diamati yaitu mesin/peralatan, metode, bahan atau material dan manusia dilakukan dengan bantuan fishbone. Dimana penyebab tersebut akan dianalisis dengan menggunakan FMEA. FMEA dilakukan dengan menuliskan nilai dari 3 aspek yaitu severity, occurance dan detection. Dimana pada Idling and Minor Stoppage penyebab yang harus segera dilakukan tindakan adalah kurangnya bahan pada saaat dijalankan mesin (48) dengan usulan yang dilakukan seperti operator harus selalu mengawasi bagian mesin. Sedangkan pada Reduced speed penyebab dengan nilai RPN tertinggi ada 2 yaitu, terjadinya kerusakan pada pulley dan cara setting yang salah, dimana keduanya harus dilakukan perbaikan. Seperti pada kerusakan pada pulley diharapkan adanya perawatan mesin yang berkala dari pihak perusahaan, dan untuk cara setting yang salah perlu dilakukannya menurunakan standar operasional yang sesuai dengan mesin sheating 3 itu sendiri. 


\section{DAFTAR PUSTAKA}

[1]. Ebeling, Charles E., 1997, An Introduction to Reliabiliry and Maintainability Engineering, Me Graw Hill Book Co., Singapore.

[2]. Almeanazel, Osama Taisir R., 2010, Total Productive Maintenance Review and Overall Equipment Effectiveness Measurement, Journal of Mechanical and Industrial Engineering, Vol. 4 No. 4, pp 517 - 522

[3]. Fahmi, Irham., 2013, Analisis Laporan Keuangan. Bandung: Alfabeta

[4]. Nakajima, S., 1988, Introduction to TPM Total Productive Maintenance. Cambridge: Productivity Press, Inc.

[5]. Roberts, J., 1997, Total Productive Maintenance (TPM), The Technology Interface, Texas: Department of Industrial and Engineering Technology, A\&M University. 